\title{
Bolu koşullarında farklı kişniş (Coriandrum sativum L.) çeşit ve popülasyonlarının verim ve kalite özelliklerinin belirlenmesi*
}

\author{
Orkun EMİRALİoĞLU ${ }^{\circledR} 1$, Gülsüm YALDIZ ${ }^{\circledR 2} 2$ \\ ${ }^{1}$ Bolu Abant İzzet Baysal Üniversitesi Fen Bilimleri Enstitüsü Tarla Bitkileri Anabilim Dalı, Bolu \\ ${ }^{2}$ Bolu Abant İzzet Baysal Üniversitesi Ziraat Fakültesi Tarla Bitkileri Bölümü, Bolu \\ *Yüksek Lisans çalışmasından alınmış olup, BAİBÜ BAP birimi tarafından desteklenmiştir (Proje No: 2016.10.07.1090).
}

Alınış tarihi: 10 Eylül 2020, Kabul tarihi: 6 Kasım 2020

Sorumlu yazar: Gülsüm YALDIZ, e-posta: g_yaldiz@hotmail.com

\section{Öz}

Bu çalışmada Bolu ekolojik koşullarında Türkiye'nin farklı bölgelerinden tedarik edilen yirmi sekiz farkl kişnişin (Coriandrum sativum L.) verim ve uçucu yağ bileşenleri belirlenmiştir. Çalışmada, çimlenme süresi (8-14 gün), çiçeklenme süresi (27-30 gün), olgunlaşma süresi (39-67 gün), bitki boyu (40.2-69 $\mathrm{cm}$ ), dal sayısı (3.6-9.6 adet), bin tane ağırlığı (5.14$16.8 \mathrm{~g})$, tohum verimi $(12.2-73.4 \mathrm{~kg} / \mathrm{da})$, hasat indeksi (\%6.3-60), biyolojik verimi (41.59-343.75 $\mathrm{kg} / \mathrm{da})$, ham yağ oranı (\%1.63-24.26), uçucu yağ oranı (\%0.3-1.3), ile uçucu yağ bileșenleri linalool (\%32-87.43), camfor (\%0.13-7.6) $\quad$-terpinene (\%0.04-13.8), p-cymene (\%0.1-15.77), $\beta$-pinene (\%0.09-5.38) arasında değişmiştir. Bolu ekolojik koşullarında tek yıllık yürütülen çalışmada bütün kişniş çeşit ve popülasyonlarının bölge şartlarında yetişebileceği, fakat araştırılan özellikler bakımından çeşit ve popülasyonlar arasında önemli farklılıklar olduğu tespit edilmiştir. Bu çalışma sonuçlarına göre bölge şartlarında tohum verimi ve uçucu yağ oranı bakımından Erzurum K.T popülasyonu ile K.T Pop-2 popülasyonu önerilebilir.

Anahtar kelimeler: Kișniș, Coriandrum sativum L., verim, sabit yağ, uçucu yağ bileşenleri

Determination of yield and quality properties of coriander (Coriandrum sativum L.) cultivar and populations in Bolu conditions

\author{
Abstract \\ In this study, research work has been carried out to \\ find out the adaptability of coriander (Coriandrum
}

sativum L.) in terms of its seed yield and the essential oil content under the climate and ecological conditions of Bolu. In the current study, 28 different coriander cultivars and populations, which were obtained from different regions of Turkey, were used as experimental materials. The variation of the investigated traits among the coriander cultivars and populations were as follows, germination time ranged between (8-14 day), flowering time (27-30 day), maturation time (39-67 day), plant height (40.2-69 cm), branch amount per plant (3.6-9.6), thousand seed weight (5.14-16.8 g), seed yield (12.2$73.4 \mathrm{~kg} / \mathrm{da})$, harvest index (\%6.3-60), biological yield (41.59-343.75 kg/da), fat oil ratio (\%1.6324.26), essential oil content (\%0.3-1.3), esential oil component, linalool (\%32-87.43), camphor (\%0.137.6), $\mathrm{\gamma}$-terpinene $(\% 0.04-13.8)$, p-cymene $(\% 0.1$ $15.77)$ and $\beta$-pinene (\%0.09-5.38). As a result of the study, it has been detected that all researched coriander cultivars and populations are cultivable under the Bolu ecological conditions, however, there are major differences between observed genotypes characteristics. According to the results of this oneyear study, the population of Erzurum K.T and the population of K.T Pop-2 can be suggested in terms of seed yield and essential oil ratio in the region.

Key words: Coriander, Coriandrum sativum L., yield, fixed oil, essential oil component.

\section{Giriş}

Kişniş (Coriandrum sativum L.) kutup bölgeleri ve tropik ülkeler haricinde dünyanın her tarafında yetişebilmekte olup, ana vatanının Doğu Akdeniz ve Mezopotamya olduğu bilinmektedir (Uhri, 2011). 
Coriandrum sativum L. türünün macrocarpum ve microcarpum olmak üzere iki alt varyetesi vardır. Dünyada daha çok tarımı yapılan varyete ise macrocarpum dir. Macrocarpum varyetesi; bin tane ağırlığ 10 gramdan fazla ve 3 mm'den büyük meyve çapına sahip olanlar, microcarpum varyetesi ise bin tane ağırlığı 10 gramdan az, 3 mm ve daha küçük meyve çapına sahip olanlar şeklinde belirtilmektedir (Diederichsen, 1996; Baydar, 2013).

Kişniş mikro besin elementleri ve besleyici maddeler bakımından oldukça zengindir ve tüm dünyada stimulan ve karminatif etkileri ya da bir çeşni olarak kullanılan aromatik meyveleri için yaygın bir şekilde yetiştirilmektedir. Doymuş yağ oranı oldukça düşük, E1 ve $K$ vitaminleri açısından iyi bir kaynaktır. Tohumları, polifenol ve uçucu yağlar yönünden, yaprakları ise vitamin içeriğince zengindir (Bhat ve ark., 2014). Kişnişin yararlanılan kısmı, toprak üstü aksamı ve tohumlarıdır. Kişniş tohumlarının kimyasal bileşiminde \%11.37 su, \%11.49 protein, \%19.15 yağ, \% 28.43 lif, \%10.53 nişasta, \%10.29 pentosan, \%1.92 şeker, \% 4.98 mineral maddeler ve \%0.84 uçucu yağ bulunmaktadır (Diederichsen, 1996). Kişniş bitkisinin yaprakları da ağrı kesici, sakinleştirici olarak kullanılmakta ve sindirim sistemi üzerinde birçok olumlu etkisinin varlığı farklı kaynaklarda belirtilmektedir (Baytop, 1984).

Kişniş, adaptasyon yeteneğinin yüksek olmasıyla Türkiye'nin her yerinde yetiştirilebilecek bitkilerden birisidir. Ilıman bölgelerde kışlık ekimlerde zarar görmezken soğuk bölgelerde kışlık ekimlerde zarar görmektedir (Kaya ve ark., 2000). Ülkemizde Mardin, Gaziantep gibi güney illerde büyük tohumlu varyetesi, Erzurum, Van, Sinop gibi doğu ve kuzey illerde ise küçük tohumlu varyetesi yaygındır (Telci ve ark., 2006). En çok Göller Bölgesinde, Ankara, Eskişehir, Mardin, Gaziantep, Denizli, Burdur, Erzurum ve Konya'da tarımı yapılabilmektedir (Kaya ve ark., 2000; Kan ve İpek, 2002; Baydar, 2013).

$\mathrm{Bu}$ çalışmada, Türkiye'nin farklı illerinden tedarik edilen kişniş popülasyon ve tescilli çeşitlerinin Bolu ekolojik koşullarında adaptasyon yeteneği, verim ve kalite özellikleri belirlenmiştir.

\section{Materyal ve Yöntem}

Araştırma 2015 yılında Abant İzzet Baysal Üniversitesi Araştırma ve Uygulama alanında Tesadüf Blokları Deneme Desenine göre üç tekerrürlü olarak yürütülmüștür.

Araştırmanın yürütüldüğü Bolu ilinin iklimi deniz iklimi ile İç Anadolu'nun karasal (bozkır) iklimi arasında bir geçiş alanında olduğundan, her iki iklimin tesiri altındadır. Denemenin yürütüldügü yılın Nisan ve Eylül dönemde ortalama sıcaklık 17.32 ${ }^{\circ} \mathrm{C}$, toplam yağış miktarı $330.9 \mathrm{~kg} / \mathrm{m}^{2}$, uzun yıllara ait ortalama sıcaklık $16.8{ }^{\circ} \mathrm{C}$ toplam yağış miktarları ise $248.1 \mathrm{~kg} / \mathrm{m}^{2}$ ‘dır (Bolu Meteoroloji Müdürlüğü).

Uygulama alanı toprak bünyesi tınlı, hafif alkali ( $\mathrm{pH}$ 7.5) , kireçli (\% 2.8) ve tuzsuz olduğu (\%0.008) saptanırken, toprak organik madde içeriği az (\%1.6), fosfor miktarı çok yüksek (23.74 ppm) ve potasyumca (38 ppm) yeterli bulunmuştur (Anonim, 2015). Denemede Erzurum, Denizli, Artvin, Rize, Burdur, Kırşehir, Mardin, Ankara ve Karaman illerinden tedarik edilen ve Artvin (Gürcistan) ve Ankara'da (Hindistan, Pakistan) ticari olarak kullanılan popülasyonlar ve Arslan, Gürbüz, KudretK, Pel-mus, Erbaa, Gamze tescilli çeşitleri olmak üzere toplam 28 materyal kullanılmıștır.

Deneme 28 Nisan 2015 tarihinde Abant İzzet Baysal Üniversitesi Araştırma ve Uygulama alanında Tesadüf Blokları Deneme Desenine göre üç tekerrürlü olarak kurulmuștur. Deneme de sıra arası $30 \mathrm{~cm}$ sira üzeri $10 \mathrm{~cm}$ olacak şekilde düzenlenmiştir. Toplam deneme alanı $33.6 \mathrm{~m} \mathrm{x} 8 \mathrm{m=}$ $268.8 \mathrm{~m}^{2}$ dir. Tohum ekimi ile birlikte taban gübresi olarak dekara 6 kg NPK (15-15-15) ve azotlu gübre olarak ise yarısı ekimle birlikte yarısı da bitkinin çiçeklenme döneminden önce olmak üzere dekara toplam $4.5 \mathrm{~kg}$ amonyum sülfat $\left(\mathrm{NH}_{4}\right)_{2} \mathrm{SO}_{4}(\% 21 \mathrm{~N})$ verilmiştir. Denemenin kurulmasıyla birlikte bakım işlemlerinin en önemli parçası olan yabancı otla olan mücadele elle ve çapa ile yapılmıştır. Parsellerde iki sıra kenar tesiri olarak bırakıldıktan sonra orta iki sıra hasat edilmiştir. Hasat işlemi 16 Temmuz-22 Eylül 2015 tarihleri arasında gerçekleştirilmiştir. Deneme de incelenen bitkisel ve agronomik özellikler İlisulu, (1973), Arslan ve Bayrak (1987), Kırıcı ve ark., (1997), Bayram, (1992) ve Karadoğan ve Oral, (1994) faydalanılarak yapılmıştır.

\section{Sabit yağ oranı (\%)}

Sabit yağ oranı analizi için, 10 g öğütülmüş tohum örnekleri n-hekzan yardımıla 6 saat süreyle ekstraksiyona tabi tutulmuş, \% sabit yağ oranı belirlenmiştir (Baydar ve Erbaş, 2014).

\section{Uçucu Yağ Oranı (\%)}

Her parselden alınan $20 \mathrm{~g}$ tohum örneklerinin clevenger cihazında 4 (dört) saat süreyle su distilasyon yöntemine tabi tutularak uçucu yağ elde edilmiştir (TSE, 2015). Daha sonra örnek miktarı ile yüzdeye oranlanarak elde edilmiştir. 
Çizelge 1. Araştırmada kullanılan bitki materyalleri ve tedarik edildiği yerler

\begin{tabular}{|c|c|c|c|c|c|}
\hline No & Kişniş Popülasyon/ Çeșit & Tedarik Edildiği Yerler & No & Kişniş Popülasyon/ Çeşit & Tedarik Edildiği Yerler \\
\hline 1 & Arslan & Ankara \tescilli çeşit & 15 & Denizli-2 & Denizli \çiftçi \\
\hline 2 & Erbaa & Samsun\tescilli çeşit & 16 & Erzurum & Erzurum \çiftçi \\
\hline 3 & Gamze & Samsun \tescilli çeşit & 17 & Erzurum K.T & Erzurum $\backslash$ aktar \\
\hline 4 & Gürbüz & Ankara \tescilli çeşit & 18 & Hindistan & Ankara \aktar \\
\hline 5 & Kudret-K & Samsun\tescilli çeşit & 19 & İslamabad & Ankara \aktar \\
\hline 6 & Pel-Mus & Samsun \tescilli çeşit & 20 & K.T Pop-1 & Ankara \TARM \\
\hline 7 & Ankara Ticari & Ankara \aktar & 21 & K.T Pop-2 & Ankara \TARM \\
\hline 8 & Antalya-1 & Antalya \aktar & 22 & Karaman & Karaman \aktar \\
\hline 9 & Artvin & Artvin \çiftçi & 23 & Kerkük F-2 & Ankara \TARM \\
\hline 10 & В.TPop-1 & Ankara \TARM & 24 & Kırşehir & Kırşehir \aktar \\
\hline 11 & Batum & Artvin \çiftçi & 25 & Kişniş Pop & Ankara \aktar \\
\hline 12 & Burdur & Burdur \aktar & 26 & Mardin B.T & Mardin \aktar \\
\hline 13 & Burdur-Beyköy & Burdur \aktar & 27 & Nazilli & Aydın \aktar \\
\hline 14 & Denizli-2 & Denizli\aktar & 28 & Rize Fındıklı & Rize \aktar \\
\hline
\end{tabular}

K.T: küçük tohum, B.T: büyük tohum

\section{Uçucu Yağ Bileşenleri (\%)}

Uçucu yağ bileșenleri analizi Abant İzzet Baysal Üniversitesi Merkez Laboratuvarında yapılmıştır. Örnekler analiz edilmek üzere 1:100 oranında metanol ile seyreltilmiştir. Örneklerin uçucu yağ bileşen analizi GC/GC-MS (Gaz kromatografisi (Thermo Scintific Trace 1300)-kütle detektör (Thermo Scintific ISQ QD)) cihazı ile kapiler kolon (TG-624; $30.0 \mathrm{~m} \times 0.25 \mathrm{~mm} \times 1.4 \mu \mathrm{m}$ ) kullanılarak gerçekleştirilmiştir. Analizde taşıyıcı gaz olarak 1.00 $\mathrm{ml} / \mathrm{dk}$ akış hızında helyum kullanılmış, örnekler cihaza $1 \mu \mathrm{l}$ olarak enjekte edilmiștir. Enjektör sıcaklı̆ğ $230^{\circ} \mathrm{C}^{\prime}$ de tutulmuş, kolon sıcaklık programı $40^{\circ} \mathrm{C}$ ( 2 dakika), $40^{\circ} \mathrm{C}$ 'den $220^{\circ} \mathrm{C}$ ye $5^{\circ} \mathrm{C}$ /dakika ve $220^{\circ} \mathrm{C}$ (10 dakika) olacak şekilde ve splitless modunda ayarlanmıștır. Bu sıcaklık programı doğrultusunda toplam analiz süresi 48 dakika olmuştur. Kütle detektörü için tarama aralığ $(\mathrm{m} / \mathrm{z})$ 35-600 atomik kütle ünitesi ve elektron bombardımanı iyonizasyonu $70 \mathrm{eV}$ ve transfer hattının sıcaklığı $280^{\circ} \mathrm{C}$ ve iyon kaynağı sıcaklığı $220^{\circ} \mathrm{C}$ kullanılmıştır, uçucu yağın bileşenlerinin teşhisinde ise WILEY ve NIST kütüphanelerinin verileri esas alınmıştır. Sonuçların bileșen yüzdeleri ve bileșenlerin teşhisi için MS dedektör kullanılarak yapılmıştır (BETUM, 2015).

\section{Verilerin Değerlendirilmesi}

Araştırmada elde edilen veriler Tesadüf Blokları Deneme Desenine göre SPSS istatistik 22 paket programı kullanılarak varyans analizine tabi tutulmuş ve Duncan çoklu karşılaştırma testi ile gruplandırılmıştır.

\section{Bulgular ve Tartışma \\ İlk Çıkış Süresi}

Denemede kişniş çeşit ve popülasyonların ilk çıkış süreleri 8-14 gün arasında değişmiş olup, erkenci çeşitler Arslan, Gürbüz, Pel-Mus, Gamze (8.gün), geçci popülasyonlar ise Burdur, Denizli-2, B.T Pop-2, Ankara Ticari, K.T Pop-2, Hindistan, Denizli-1, Antalya-1, Artvin, Rize Findıklı, Batum, İslamabat, Burdur Beyköy, Kırşehir popülasyonları ile Erbaa çeşidi olarak belirlenmiştir (14.gün) (Çizelge 2).

Kişniş çeşit ve popülasyonları ile yapılan çalışmalarda; Konya'da yazlık olarak yetiștirilen kişniş hatlarında tamamen çıkış sureleri 14-18 gün (Kan ve İpek, 2002), Erzurum koşullarında 19.46 ile 20.80 gün (Sezek, 2014), Samsun ekolojik koşullarında \%50 çıkış süresi yazlık ekimde 14-18 gün, kışlık ekimde 16-20 gün (Yurum, 2012) olduğu bildirilmiştir. Araştırıcıların bulguları ile bizim bulgularımız arasındaki farkın, ekolojik faktörler ve farklı ekim zamanlarından kaynaklandığı düşünülmektedir. Ayrıca ilk çıkışlar hemen görüldükten sonra tarih almamızın çıkışlardaki farkın bir diğer nedeni olabilir.

\section{İlk Çiçeklenme Süresi}

Araştırmada kişniş çeşit ve popülasyonların ilk çiçek açma sürelerinde istatistiki olarak anlamlı ölçüde farklılıklar belirlenmiştir (Çizelge 2). İlk çiçeklenme süreleri 27-30 gün arasında değişmiştir. Pel-Mus 
28.gün, Denizli-2, Ankara Ticari, Denizli-1, İslamabad, Kırşehir 29.gün, Hindistan, BurdurBeyköy, Antalya-1, Rize Fındıklı, Batum 30.gün, diğer çeşit ve popülasyonlar ise 27.günde çiçeklenmiştir (Çizelge 2).

İlk çiçeklenme süresi ile yapılan çalışmalar incelendiğinde, Kan ve İpek, (2002), Konya'da yazlık olarak yetiştirilen kişniş hatlarında 48-61 gün; Yalçın, (2016), Erzurum ekolojik koşullarında 74.3 gün (Telci II) ile 82.0 gün (Telci I), Sezek, (2014) Erzurum koșullarında kișniş çeşitlerinde (Erbaa, Gamze, Gürbüz ve Kudret-K) 43.25-63.5 gün, Yurum,
(2012), Samsun ekolojik koşullarında yazlık ekimde 51-57 gün, kışlık ekimde 141-145 günde olduğunu bildirmişlerdir. Çalışmamızda, kişniş çeşit ve popülasyonları, Yurum, (2012)'un Gamze, Erbaa, Pelmus, Kudret-K; Sezek, (2014)'in Gamze, Erbaa, Kudret-K, Gürbüz; Kalkan, (2015)'ın Gamze, KudretK; Yalçın, (2016)'ın Gamze, Erbaa, Kudret-K, Pel-Mus, Gürbüz çeşitlerinden daha erken çiçeklenmişlerdir. Bu durumun ekolojik koşullar, farklı ekim zamanları ile ilk çiçekler görüldükten sonra tarih almamızdan kaynaklandığı düşünülmektedir.

Çizelge 2. Farklı kişniş popülasyon ve çeşitlerinin fenolojik ve morfolojik özellikleri

\begin{tabular}{|c|c|c|c|c|c|c|}
\hline $\begin{array}{c}\text { Popülasyon ve } \\
\text { çeșitler }\end{array}$ & $\begin{array}{l}\text { İlk çıkış } \\
\text { (gün) }\end{array}$ & $\begin{array}{l}\text { İlk çiçeklenme } \\
\text { (gün) }\end{array}$ & $\begin{array}{l}\text { İlk olgunlaşma } \\
\text { (gün) }\end{array}$ & $\begin{array}{l}\text { Bitki boyu } \\
(\mathrm{cm})\end{array}$ & $\begin{array}{l}\text { Dal sayısı } \\
\text { (adet) }\end{array}$ & $\begin{array}{c}\text { Biyolojik verim } \\
\text { (kg/da) }\end{array}$ \\
\hline Arslan & $8 d$ & $27 b$ & $40 \mathrm{~d}$ & $53.0 \mathrm{ab}$ & $5 \mathrm{ljk}$ & $108.5 \mathrm{ij}$ \\
\hline Erbaa & $14 \mathrm{ab}$ & $27 b$ & $52 c$ & $53.2 \mathrm{ab}$ & $7 d-g$ & $128.8 \mathrm{~h}$ \\
\hline Gamze & $8 d$ & $27 \mathrm{~b}$ & $41 d$ & $59.7 \mathrm{ab}$ & $6 \mathrm{fgh}$ & $168.4 \mathrm{~g}$ \\
\hline Gürbüz & $8 d$ & $27 b$ & $43 d$ & $57.8 \mathrm{ab}$ & $6 \mathrm{gh} 1$ & $72.0 \mathrm{~lm}$ \\
\hline Kudret-K & $12 \mathrm{bc}$ & $27 b$ & $53 c$ & $62.8 \mathrm{ab}$ & $6 \mathrm{ghl}$ & $210.1 \mathrm{e}$ \\
\hline Pel-Mus & $8 d$ & $28 b$ & $67 a$ & $69.0 \mathrm{a}$ & $9 \mathrm{ab}$ & $321.8 b$ \\
\hline AnkaraTicari & $14 \mathrm{ab}$ & $29 a b$ & $52 c$ & $65.4 \mathrm{ab}$ & $8 a b c$ & $128.1 \mathrm{~h}$ \\
\hline Antalya-1 & $14 \mathrm{ab}$ & $30 a$ & $63 b$ & $56.0 \mathrm{ab}$ & $8 \mathrm{bcd}$ & $239.9 d$ \\
\hline Artvin & $14 \mathrm{ab}$ & $27 b$ & $41 d$ & $63.3 \mathrm{ab}$ & $8 \mathrm{bcd}$ & $246.7 d$ \\
\hline B.T.Pop-1 & $14 \mathrm{ab}$ & $27 b$ & $41 d$ & $51.2 \mathrm{ab}$ & $5 \mathrm{jkl}$ & 83.6klm \\
\hline Batum & $14 \mathrm{ab}$ & $30 a$ & $62 b$ & $49.8 \mathrm{ab}$ & $8 \mathrm{bcd}$ & $273.7 c$ \\
\hline Burdur & $14 \mathrm{ab}$ & $27 b$ & $66 a b$ & $53.2 \mathrm{ab}$ & $5 \mathrm{jkl}$ & $286.5 c$ \\
\hline Burdur Beyköy & $14 \mathrm{ab}$ & $30 a$ & $64 \mathrm{ab}$ & $55.0 \mathrm{ab}$ & $4 \mathrm{klm}$ & $238.0 \mathrm{~d}$ \\
\hline Denizli-1 & $14 \mathrm{ab}$ & $29 a b$ & $62 \mathrm{~b}$ & $67.4 \mathrm{a}$ & $8 a b c$ & $277.2 \mathrm{c}$ \\
\hline Denizli-2 & $14 \mathrm{a}$ & $29 \mathrm{ab}$ & $66 a b$ & $58.0 \mathrm{ab}$ & $9 a$ & $186.1 \mathrm{f}$ \\
\hline ErzurumK.T & $13 a b$ & $27 b$ & $41 \mathrm{~d}$ & $45.2 \mathrm{ab}$ & $7 \mathrm{efg}$ & $107.7 \mathrm{ij}$ \\
\hline ErzurumB.T & $10 \mathrm{~cd}$ & $27 b$ & $39 d$ & $60.2 \mathrm{ab}$ & $3 n$ & $343.7 a$ \\
\hline Hindistan & $14 \mathrm{ab}$ & $30 a$ & $52 c$ & $55.6 \mathrm{ab}$ & $9 a b$ & $79.4 \mathrm{klm}$ \\
\hline İslamabad & $14 \mathrm{ab}$ & $30 a$ & $67 a$ & $63.2 \mathrm{ab}$ & $8 a b c$ & $216.6 \mathrm{e}$ \\
\hline К.T.Pop-1 & $12 \mathrm{bc}$ & $27 b$ & $40 \mathrm{~d}$ & $54.6 \mathrm{ab}$ & $6 \mathrm{fgh}$ & $95.1 \mathrm{jk}$ \\
\hline К.Т.Pop-2 & $14 \mathrm{ab}$ & $27 b$ & $41 d$ & $64.6 \mathrm{ab}$ & $8 b-e$ & 113.3hi \\
\hline Karaman & $10 \mathrm{~cd}$ & $27 b$ & $41 d$ & $40.6 b$ & $4 j-m$ & $41.6 n$ \\
\hline Kerkük F-2 & $12 \mathrm{bc}$ & $27 b$ & $53 c$ & $40.2 b$ & $7 c-f$ & $88.7 \mathrm{kl}$ \\
\hline Kişehir & $14 \mathrm{ab}$ & $29 a b$ & $67 a$ & $63.7 \mathrm{ab}$ & $7 c-f$ & $161.4 \mathrm{~g}$ \\
\hline Kișniş Pop & $12 \mathrm{bc}$ & $27 b$ & $41 d$ & $60.8 \mathrm{ab}$ & $7 c-f$ & 113.2hi \\
\hline Mardin B.T & $12 \mathrm{ab}$ & $27 b$ & $42 \mathrm{~d}$ & $50.6 \mathrm{ab}$ & $4 \mathrm{~lm}$ & $67.9 \mathrm{~m}$ \\
\hline Nazilli & $12 \mathrm{bc}$ & $27 b$ & $40 \mathrm{~d}$ & $46.4 \mathrm{ab}$ & $4 j-m$ & $72.0 \mathrm{~lm}$ \\
\hline Rize Fındıklı & $14 \mathrm{ab}$ & $30 a$ & $65 \mathrm{ab}$ & 61.8ab & $5 \mathrm{hij}$ & $203.8 \mathrm{e}$ \\
\hline Ortalama & 12 & 28 & 51 & 56,5 & 6 & 166.9 \\
\hline $\mathrm{F}$ & $11.2^{* *}$ & $7.6^{* *}$ & $103.3^{* *}$ & $1.7^{* *}$ & $27.9^{* *}$ & $329.3^{* *}$ \\
\hline
\end{tabular}

${ }^{* *} \mathrm{p}<0.01$ önem seviyesi

\section{İlk Olgunlaşma Süresi}

Çizelge 2'de görüldüğü üzere kişniş popülasyon ve çeşitlerinin olgunlaşma tarihleri istatistiki açıdan önemli bulunmuştur $(\mathrm{p}<0.01)$. Olgunlaşma süresi 3967 gün arasında değişmiş olup, en erken olgunlaşma süresi Erzurum B.T popülasyonunda görülmüş olup, bunu Nazilli, Arslan, K.T Pop-1 takip etmiştir. En geç olgunlaşma ise İslamabad, Kırşehir popülasyonları ile Pel-Mus çeşidinde görülmüştür.

Konu ile ilgili literatürlerde; olgunlaşma süresinin, çeșit ve popülasyonlara göre 82.4-129.7 gün arasında değiştiği belirtilmiştir (Karadoğan ve Oral, 1994; Kan ve İpek, 2002; Yurum, 2012; Sezek, 2014; Kalkan, 2015; Yalçın, 2016). Bu çalışmada kişniş çeşit ve popülasyonlarının olgunlaşma sürelerinin; yazlık ekim yapan Sezek, (2014)'in Gamze, Erbaa, Kudret-K, Gürbüz çeşitleri; Kalkan (2015)' in Gamze, Kudret-K çeşitleri ve Yalçın (2016)' nın Gamze, Kudret-K, Pel-Mus, Erbaa ve Gürbüz çeşitlerinden daha kısa sürdüğü belirlenmiştir. Aynı çeşitler ve benzer ekim zamanına rağmen olgunlaşma süreleri arasındaki farklılık ekolojik koşullar, yetiştirme 
teknikleri ile ilk olgunlaşan tohumlar görüldükten sonra tarih almamızdan kaynaklandığı düşünülmektedir.

\section{Bitki Boyu}

Kişniş çeşit ve popülasyonlarının bitki boyu değerleri istatistiki açıdan önemli bulunmuştur (Çizelge 2). Bitki boyu değerleri 40.26-69.06 cm arasında değişmiştir. Kişniş de en yüksek ortalama bitki boyu değeri Pel-Mus çeşidinde, en düşük bitki boyu değeri ise Kerkük F-2 popülasyonunda tespit edilmiştir. Bulgularımız, farklı ekolojilerde kişniş genotipleri ile yapılan çalışmalardan Turhan ve ark., (2005) $60 \mathrm{~cm}$ Karadoğan ve Oral, (1994), $66.6 \mathrm{~cm}$ Kan ve İpek, (2002) 40.8-58.5 cm Gümüşçü ve ark., (2006) 49.70-68.73 cm Kalkan, (2015) $59.66 \mathrm{~cm}$ bildirdiği değerler ile benzerlik göstermekle birlikte, tescilli kişniş çeşitlerinden Erbaa $89.1 \mathrm{~cm}$, Gamze $66.3 \mathrm{~cm}$, Pel-Mus $90.4 \mathrm{~cm}$ ve Kudret-K $83.6 \mathrm{~cm}$, Gürbüz $83 \mathrm{~cm}$, Arslan $75 \mathrm{~cm}$ biraz düşük çıkmıştır (Anonim, 2016).

\section{Dal sayısı}

Çizelge 2' de görüldüğü üzere; kişniş çeşit ve popülasyonları arasındaki ortalama dal sayısı değerleri istatistiki açıdan önemli bulunmuş olup, dal sayısı 3-9 adet/bitki arasında değişmiştir. En fazla ortalama dal sayısı Denizli-2 popülasyonunda, en az ortalama dal sayıs ise Erzurum B.T popülasyonunda tespit edilmiștir.

Kişniş çeşit ve popülasyonlarında bitki başına ortalama dal sayısı değerleri, Kan ve İpek, (2002) 3.8-5.8 adet, Gümüșçü ve ark., (2006) 7.67-10.1 adet Özel ve ark., (2009) 3.1-7.0 adet, Kizll ve İpek, (2004) 6.87-8.37 adet ile benzer değerler göstermiştir. Tescilli çeşitleri içeren çalışmalar ile kıyaslandığında bulgularımızın; Yurum, (2012)'un Gamze, Erbaa, Kudret-K çeşitlerinden düşük, Sezek, (2014)'in Gamze, Erbaa, Kudret-K, Gürbüz, Kalkan (2015)'nn Gamze, Kudret-K, Demir, (2015)'in Gamze, Pel-Mus, Erbaa, Kudret-K, Yalçın (2016)'nın Gamze, Pel-Mus, Erbaa, Kudret-K, Gürbüz ve Gücük, (2014)'ün altı tescilli çeşit değerlerinden yüksek olduğu belirlenmiștir.

\section{Biyolojik Verim}

Kişniş popülasyon ve çeşitlerinin biyolojik verim değerleri değerleri 41.59-343.75 kg/da arasında değișmiștir. Biyolojik verimde en yüksek değer Erzurum K.T. popülasyonundan, en düşük değer ise Karaman popülasyonundan elde edilmiştir (Çizelge 2).
Farklı genotipler ile yapılan çalışmalarda kişnişin biyolojik verimi; Avcı ve ark., (2005) 226.35-555.32 kg/da, Yalçın (2016) 307 - $406.3 \mathrm{~kg} / \mathrm{da}$, Kaya ve ark., (2000) 228.3-347.3 kg/da, Gümüşçü ve ark., (2007), 265.2-400.7 kg/da, Arabacı ve Bayram, (2005) $207.8-447.3 \mathrm{~kg} / \mathrm{da}$ olarak belirtilmiştir. $\mathrm{Bu}$ çalışmada elde edilen sonuçların Kaya ve ark., (2000) dışında diğer araştırıcıların bulgularından düşük olmasının nedeni ekolojik koşullar, farklı genotipler ve ekim zamanları olabilir.

\section{Hasat İndeksi}

Kişniş popülasyon ve çeşitlerinin hasat indeksi istatistiki açıdan önemli bulunmuş olup, hasat indeksi \%6.33-60 arasında değişmiştir. Hasat indeksi değeri en yüksek Erzurum B.T popülasyonunda bulunurken, bunu Kırşehir, B.T Pop-1, Erbaa popülasyonları takip etmiştir. En düşük değer ise Batum popülasyonunda tespit edilmiştir (Çizelge 3). Çalışmada elde edilen kişniş çeşit ve popülasyonlarına ait ortalama hasat indeksi değerleri, Kandemir, (2010) \% 0.28-0.38, Gök, (2011) \% 29-42 değerleri ile kısmen benzerlik göstermektedir.

\section{Bin Tane Ağırlığı}

Çizelge 3'te görüldüğü üzere; kişniş çeşit ve popülasyonlarının ortalama bin tane ağırlığı değerleri değerleri 5.14-16.58 g arasında değişmiştir. Kişniş çeşit ve popülasyonlarında ortalama bin tane ağırlığında en yüksek değere Arslan çeşidinde, en düşük değere ise Hindistan popülasyonunda ulaşılmıştır.

Farklı ekolojilerde yürütülen kişniş çeşit ve popülasyonları ile ilgili bin tane ağırlığı değerleri, Kızıl ve İpek, (2004) 13.02-13.16 g, Mert ve Kırıcı, (1998) 5.77-11.05 g, Demir, (2015) 9.9 g, Kalkan, (2015) 9.79 g, Yurum, (2012) 7.16-8.82 g, Özel ve ark.., (2009) 8.1-11.4 g arasında değişmiştir. Çalışmamıza ait bin tane ağırlı̆̆ı değerleri araştırıcıların belirttikleri değerler arasındadır.

\section{Dekara Verim}

Kişniş popülasyon ve çeşitlerinin dekara tohum verimi yönünden aralarındaki farklılıklar istatistiki açıdan önemli bulunmuş olup, $13.28 \mathrm{~kg} / \mathrm{da}$ ile 73.42 $\mathrm{kg} / \mathrm{da}$ arasında değișmiştir. En yüksek tohum verimi Erzurum K.T. popülasyonundan, en düşük tohum verimi ise Hindistan popülasyonunda belirlenmiştir (Çizelge 3). Kişniş çeşit ve popülasyonlarına ait ortalama tohum verimi; Gümüşçü ve ark.. (2007) 
166.3 kg/da, Yurum (2012) 74.96-109.6 kg/da, Kızll ve İpek, (2004) 98.5-181.4 kg/da, Mert ve Kırıcl, (1998) 96.55-172.60 kg/da, Gök (2011) 13.1-58 $\mathrm{kg} / \mathrm{da}, \mathrm{Avcl}$ ve ark., (2005) 56.60- $89.57 \mathrm{~kg} / \mathrm{da}$, Kandemir, (2010) 104.05-225.17 kg/da, Demir, (2015) 227.9 kg/da, Tunçtürk, (2006) $129.50 \mathrm{~kg} / \mathrm{da}$ olarak bildirilmiştir. Çalışmadan elde edilen verim değerleri; Avcı ve ark., (2005) ile Gök (2011) bulguları ile benzerlik gösterirken, diğer araştırıcıların bulgularından düşük çıkmıştır. Bulgularımızın araştırıcıların verilerinden düşük çıkmasının sebebinin farklı genotipler ile ekim zamanı farklılı̆̆ından kaynaklandığı düşünülmektedir.

Çizelge 3. Farklı kişniş popülasyon ve çeşitlerinin hasat indeksi, bin tane ağırlığı, tohum verimi, sabit yağ oranı

\begin{tabular}{|c|c|c|c|c|}
\hline Populasyon ve çeșitler & Hasat indeksi (\%) & 1000 tohum ağırlığı (g) & Tohum verimi (kg/da) & Sabit yağ içeriği (\%) \\
\hline Arslan & $20.00 \mathrm{jk}$ & $16.58 \mathrm{a}$ & $21.59 \mathrm{ij}$ & $1.63^{\mathrm{l}}$ \\
\hline Erbaa & $33.00 \mathrm{~cd}$ & $9.54 \mathrm{~d}-\mathrm{g}$ & $42.51 \mathrm{~g}$ & $2.33^{\mathrm{lk}}$ \\
\hline Gamze & 28.33efg & $10.95 \mathrm{~cd}$ & $47.61 \mathrm{ef}$ & $19.36^{\mathrm{C}}$ \\
\hline Gürbüz & $26.33 \mathrm{fgh}$ & $9.53 \mathrm{~d}-\mathrm{g}$ & $19.43 \mathrm{kl}$ & $21.33^{b}$ \\
\hline Kudret-K & $25.00 \mathrm{gh} ı$ & $8.92 \mathrm{f}-1$ & $51.98 \mathrm{~d}$ & $3.80^{\mathrm{k}}$ \\
\hline Pel-Mus & 12.661 & $7.77 \mathrm{~h}-\mathrm{k}$ & $40.77 \mathrm{~g}$ & $7.63^{\mathrm{j}}$ \\
\hline Ankara Ticari & $26.33 \mathrm{fgh}$ & 7.301-l & $33.87 \mathrm{~h}$ & $3.10^{\mathrm{lk}}$ \\
\hline Antalya-1 & 12.661 & $7.12 \mathrm{jkl}$ & $30.98 \mathrm{~h}$ & $19.06^{\mathrm{C}}$ \\
\hline Artvin & $18.66 \mathrm{jk}$ & $7.271-1$ & $45.97 \mathrm{f}$ & $2.76^{\mathrm{lk}}$ \\
\hline B.T.POP-1 & $36.00 \mathrm{bc}$ & $15.71 \mathrm{a}$ & 30.031 & $7.36^{\mathrm{j}}$ \\
\hline Batum & $6.33 n$ & $6.48 \mathrm{klm}$ & 17.231 & $24.26^{\mathrm{a}}$ \\
\hline Burdur & $20.33 \mathrm{jk}$ & $5.56 \mathrm{~lm}$ & $59.06 c$ & $7.83^{j}$ \\
\hline Burdur Beyköy & $20.00 \mathrm{jk}$ & $6.19 \mathrm{klm}$ & 47.33ef & $8.23^{\mathrm{j} 1}$ \\
\hline Denizli-1 & $19.00 \mathrm{jk}$ & $5.80 \mathrm{~lm}$ & $52.66 \mathrm{~d}$ & $15.20^{\mathrm{fe}}$ \\
\hline Denizli-2 & $27.00 \mathrm{fgh}$ & $6.36 \mathrm{klm}$ & 50.31de & $10.06^{\mathrm{h}}$ \\
\hline Erzurum K.T & $60.00 \mathrm{a}$ & $13.35 b$ & $64.67 \mathrm{~b}$ & $9.70^{\mathrm{lh}}$ \\
\hline Erzurum B.T & $21.33 \mathrm{ij}$ & $6.23 \mathrm{klm}$ & $73.42 \mathrm{a}$ & $16.83^{\mathrm{de}}$ \\
\hline Hindistan & $17.00 \mathrm{k}$ & $5.14 \mathrm{~m}$ & $13.28 \mathrm{~m}$ & $17.10^{\mathrm{d}}$ \\
\hline İslamabad & $11.33 \mathrm{~lm}$ & $8.36 \mathrm{~g}-\mathrm{j}$ & $22.44 \mathrm{i}$ & $3.26^{\mathrm{lk}}$ \\
\hline К.Т.РОР-1 & $30.00 \mathrm{def}$ & $10.24 \mathrm{def}$ & 28.711 & $3.56^{\mathrm{lk}}$ \\
\hline К.Т.РОР-2 & 27.33efgh & $10.81 \mathrm{~cd}$ & $31.02 \mathrm{~h}$ & $10.53^{\text {hg }}$ \\
\hline Karaman & $32.33 d$ & $12.38 \mathrm{bc}$ & $13.37 \mathrm{~m}$ & $20.10^{\mathrm{cb}}$ \\
\hline Kerkük F-2 & $25.00 \mathrm{gh} ı$ & $12.29 \mathrm{bc}$ & $22.14 \mathrm{ij}$ & $15.06^{\mathrm{fe}}$ \\
\hline Kışehir & $39.00 \mathrm{~b}$ & 7.371-l & $63,16 b$ & $19.46^{\mathrm{C}}$ \\
\hline Kişniş Pop & $25.00 \mathrm{gh}$ & 10.18def & 28.511 & $12.10^{\mathrm{g}}$ \\
\hline Mardin B.T & $24.00 \mathrm{hl}$ & $9.13 \mathrm{e}-\mathrm{h}$ & $16.48 \mathrm{~lm}$ & $13.93^{\mathrm{f}}$ \\
\hline Nazilli & $31.00 \mathrm{de}$ & $10.34 \mathrm{def}$ & $22.29 \mathrm{ij}$ & $11.50^{\mathrm{hg}}$ \\
\hline Rize Fındıklı & $8.66 \mathrm{mn}$ & $6.37 \mathrm{klm}$ & 17.521 & $2.60^{\mathrm{lk}}$ \\
\hline Ortalama & 24.41 & 9.04 & 36.01 & 11.05 \\
\hline $\mathrm{F}$ & $99.23^{* *}$ & $29.4^{* *}$ & $520.2^{* *}$ & $126.1^{* *}$ \\
\hline
\end{tabular}

${ }^{* *} \mathrm{p}<0.01$ önem seviyesi

\section{Sabit yă̆ oranı}

Araştırmada elde edilen sonuçlar incelendiğinde kişniş popülasyon ve çeşitlerinin sabit yağ oranı istatistiki açıdan önemli bulunmuş, \%1.63-24.26 arasında değişmiştir. En yüksek sabit yağ oranı Batum popülasyonunda, en düşük sabit yağ oranı ise Arslan çeşidinde tespit edilmiştir (Çizelge 3). Konu ile ilgili literatürler incelendiğinde 12.25-16.95 kg/da Yurum, (2012) ve \%17.8-19.15 Şarer, (2018) bulguları, bizim bulgularımızla benzerlik göstermektedir.

\section{Uçucu Yağ Oranı}

Çizelge 4'de görüleceği üzere kişniş popülasyon ve çeşitlerinin uçucu yağ oranı istatistiki açıdan önemli bulunmuş olup, \%0.33-1.33 arasında değișmiștir. En yüksek uçucu yağ oranı K.T. Pop-2, en düşük uçucu 
yağ oranı ise Ankara ticari popülasyondan elde edilmiştir.

Avrupa farmokopesine göre kişniş uçucu yağ değerinin Hint kökenli olanlarda $\% 0.2$, Rusya kökenli olanlarda ise \%0.8-1 ve $\% 0.5^{\prime}$ den az olmaması istenmektedir (Wagner ve ark., 1984). Çalışmamızda Ankara ticari popülasyonu haricinde standartların altında kalan çeşit ve popülasyon bulunmamaktadır. Türk Gıda Kodeksi Baharat tebliğine göre kișniște öğütülmemiș baharatın uçucu yağ oranının $0.4 \mathrm{ml} / 100 \mathrm{~g}^{\prime} \mathrm{dan}$ az olmaması istenmektedir (Anonim, 2013).

Konu ile ilgili literatürler incelendiğinde; kişniş uçucu yağ oranı İnan ve ark., (2014) \% 0.21-0.69, Avcl ve ark., (2005) \% 0.06 -\% 0.30 Mert ve Kırıcl, (1998) \% 0.34-0.56, Kizıl ve İpek, (2004) \% 0.2870.318 Yurum (2012) \% 0.30-0.50, Gök (2011) \% 0.27-0.60, Yalçın, (2016) \% 0.32 -0.71, Beyzi ve Güneş, (2018) \% 0.23 - 0.39 olarak belirlenmiştir.

Denemenin kişniş çeşit ve popülasyonlarının ortalama uçucu yağ oranları, araştırıcıların değerlerinden yüksek çıkmıştır.

\section{Uçucu Yağ Bileşenleri}

Avrupa farmokopesine göre kişniş uçucu yağ bileşenlerinden, linalool oranı \%50-70 arasında olup, terpen hidrokarbonları ise ( $\beta$-pinen, $\gamma$ terpinen, ve Myrcene) yaklaşık olarak uçucu yağ bileșenlerinin \%20'sini oluşturur (Wagner ve ark., 1984). Kişniş çeşit ve popülasyonlarında linalool değerleri \% 32-87.43 arasında tespit edilmiștir. En yüksek değer Hindistan popülasyonundan elde edilmiş olup, bunu Antalya-1, Burdur-Beyköy, Kırşehir popülasyonları takip etmiştir. En düşük değerler ise Gürbüz, Pel-Mus, Kudret-K çeşitlerinde tespit edilmiştir. Kişniş çeşit ve popülasyonlarından Gamze çeşidi dışında Avrupa farmokopelerinde belirtilen değerler arasında linalool değerlerine sahiptir.

Kişniş ortalama p-cymene değerleri \% $0.1-15.77$ arasında değişmiş olup, en yüksek p- cymene değeri sırasıyla Pel-Mus, Erzurum B.T, Kudret-K, Gürbüz çeșitlerinde tespit edilmiștir. En düșük p- cymene değeri sırasıyla B.T Pop-2, Arslan, Antalya-1, Kırşehir çeşit ve popülasyonlarında tespit edilmiştir (Çizelge 4). Çalışmada У-terpinene değerleri \% 0.04-13.8 arasında bulunmuştur. En yüksek değerler sırasıyla Pel-Mus, Gürbüz, Kudret-K çeşitlerinde, en düşük değerler ise sirasıyla Arslan, Antalya-1, B.T Pop-2, Kırşehir popülasyonlarında tespit edilmiştir.
Kişniş çeşit ve popülasyonlarının $\beta$-pinene değerleri \%0.09-5.38 arasında değişmiştir. En yüksek $\beta$ pinene değeri \%5.38 ile Gürbüz çeşidinde tespit edilirken bunu Pel-Mus, Kudret-K çeşitleri takip etmiştir. En düşük $\beta$-pinene değeri sırasıyla Gamze, Kırşehir, Arslan, Antalya-1 çeşit ve popülasyonlarında saptanmıştır.

Kişniş çeşit ve popülasyonlarının camphor değeri \% 0.13-7.62 arasında değișmiştir. En yüksek camphor değeri Arslan çeșidinde tespit edilirken, bunu Kırşehir, Antalaya-1 ve Artvin popülasyonları takip etmiştir. En düşük camphor değeri Burdur Beyköy popülasyonunda saptanmış olup, bunu Denizli-1, Hindistan, Rize-Fındıklı popülasyonları takip etmiștir.

Kişniş bitkisinde yapılan farklı çalışmalarda linalool oranlarl; Diederichsen (1996) \% 60 - 80, İşcan ve ark., (2004) \% 67.1, Kaya ve ark., (2000)\% 79.86 80.54, Cioanca ve ark., (2013) \%40.9- 79.9, Delaquis ve ark., (2002) \% 69.80, Özel ve ark., (2010) \% 76.12 - 82.74, Gücük (2014) \% 53 - 74, İnan ve ark., (2014) \% 84.6-90.1 olarak tespit edilmiștir.

Bu çalışmada elde edilen linalool oranı, diğer yapılan çalışmalar ile benzerlik göstermektedir. Camphor bileşeni ile ilgili yapılan çalışmalara bakıldığında; İscan ve ark.. (2004) \% 6.6, Zoubiri ve Baaliouamer (2010) \% 1.85, Gök (2011) \% 1.9 - 4.4, Özel ve ark.. (2010) \% 2.56 - 3.44 ve Delaquis ve ark.. (2002) \% 5.20 arasında değiştiğini bildirmişlerdir. Araştırıcıların bulguları bu çalışmadan elde edilen camphor oranları ile benzerlik göstermekle birlikte, üst değerlerimizin altındadır.

$\gamma$-terpinene bileşeni ile ilgili yapılan çalışmalara bakıldığında; Delaquis ve ark., (2002) \% 5.3, Gök, (2011) \% 7.0 - 8.0, Cioanca ve ark., (2013) (\%0.113.6), Özel ve ark., (2010) \% 3.71-6.20 arasında değiştiğini bildirmişlerdir. Bu çalışmadan elde edilen $\gamma$-terpinene değerleri, Cioanca ve ark., (2013) ile paralel iken, diğer araştırıcıların bulgularından yüksek bulunmuştur. $\mathrm{Bu}$ araştırmada Pel-Mus, Kudret-K, Gürbüz çeşitleri ile Erzurum B.T popülasyonunda ortalama p-cymene değerleri araştırıcıların bulgularından yüksek bulunmuştur.

p-cymene bileşeni ile ilgili yapılan çalışmalara bakıldığında; Beyzi ve Güneş, (2017) \% 0.17 - 0.82 , İşcan ve ark., (2004) \% 3.3, Özel ve ark., (2010) \% 3.88-6.29 değerlerinden bizim bulgularımız yüksek çlkmıştır. 
Çizelge 4. Farklı kişniş popülasyon ve çeşitlerinin uçucu yağ oranı ve bileşenleri

\begin{tabular}{|c|c|c|c|c|c|c|}
\hline \multirow[b]{2}{*}{$\begin{array}{c}\text { Populasyon ve } \\
\text { çeșitler }\end{array}$} & \multirow[b]{2}{*}{$\begin{array}{l}\text { Uçucu yă } \\
\text { oranı(\%) }\end{array}$} & \multicolumn{5}{|c|}{ Uçucu yağ bileșenleri(\%) } \\
\hline & & Linalool & $\begin{array}{c}\text { Populasyon ve } \\
\text { çeşitler }\end{array}$ & $\begin{array}{l}\text { Uçucu yağ } \\
\text { oranı(\%) }\end{array}$ & Linalool & $\begin{array}{c}\text { Populasyon ve } \\
\text { çeşitler }\end{array}$ \\
\hline R.Time & & 23.82 & R.Time & & 23.82 & R.Time \\
\hline Arslan & $0.57 \mathrm{hl}$ & $67.67 \mathrm{u}$ & Arslan & $0.57 \mathrm{hl}$ & $67.67 \mathrm{u}$ & Arslan \\
\hline Erbaa & $0.73 \mathrm{~d}-\mathrm{h}$ & $82.04 \mathrm{~g}$ & Erbaa & $0.73 \mathrm{~d}-\mathrm{h}$ & $82.04 \mathrm{~g}$ & Erbaa \\
\hline Gamze & $0.96 \mathrm{a}-\mathrm{g}$ & 81.861 & Gamze & $0.96 a-g$ & 81.861 & Gamze \\
\hline Gürbüz & $0.80 c-h$ & $32.00 \mathrm{z}$ & Gürbüz & $0.80 c-h$ & $32.00 \mathrm{z}$ & Gürbüz \\
\hline Kudret-K & $0.96 a-g$ & $56.30 v$ & Kudret-K & $0.96 a-g$ & $56.30 \mathrm{v}$ & Kudret-K \\
\hline Pel-Mus & $1.03 a-e$ & $45.80 y$ & Pel-Mus & $1.03 a-e$ & $45.80 y$ & Pel-Mus \\
\hline Ankara Ticari & 0.331 & $80.28 \mathrm{j}$ & Ankara Ticari & 0.331 & $80.28 \mathrm{j}$ & Ankara Ticari \\
\hline Antalya-1 & $1.23 \mathrm{ab}$ & $86.03 \mathrm{~b}$ & Antalya-1 & $1.23 \mathrm{ab}$ & $86.03 \mathrm{~b}$ & Antalya-1 \\
\hline Artvin & $1.13 \mathrm{abc}$ & $81.22 \mathrm{i}$ & Artvin & $1.13 \mathrm{abc}$ & $81.22 \mathrm{i}$ & Artvin \\
\hline B.T.POP-1 & $0.80 \mathrm{c}-\mathrm{h}$ & 77.850 & B.T.POP-1 & $0.80 c-h$ & 77.850 & B.T.POP-1 \\
\hline Batum & $0.90 \mathrm{~b}-\mathrm{h}$ & $82.96 \mathrm{f}$ & Batum & $0.90 \mathrm{~b}-\mathrm{h}$ & $82.96 \mathrm{f}$ & Batum \\
\hline Burdur & $0.70 \mathrm{e}-\mathrm{h}$ & 76.49ö & Burdur & $0.70 \mathrm{e}-\mathrm{h}$ & 76.49ö & Burdur \\
\hline Burdur Beyköy & $1.20 \mathrm{ab}$ & $85.22 \mathrm{c}$ & Burdur Beyköy & $1.20 \mathrm{ab}$ & $85.22 \mathrm{c}$ & Burdur Beyköy \\
\hline Denizli-1 & $0.90 \mathrm{~b}-\mathrm{h}$ & $66.90 \ddot{u}$ & Denizli-1 & $0.90 \mathrm{~b}-\mathrm{h}$ & $66.90 \ddot{u}$ & Denizli-1 \\
\hline Denizli-2 & $0.73 \mathrm{~d}-\mathrm{h}$ & $78.25 \mathrm{mn}$ & Denizli-2 & $0.73 \mathrm{~d}-\mathrm{h}$ & $78.25 \mathrm{mn}$ & Denizli-2 \\
\hline Erzurum K.T & $0.90 \mathrm{~b}-\mathrm{h}$ & 69.67 ş & Erzurum K.T & $0.90 \mathrm{~b}-\mathrm{h}$ & $69.67 s$ & Erzurum K.T \\
\hline Erzurum B.T & $0.60 \mathrm{gh} \mathrm{l}$ & $83.15 \mathrm{e}$ & Erzurum B.T & $0.60 \mathrm{gh}$ & $83.15 \mathrm{e}$ & Erzurum B.T \\
\hline Hindistan & $1.03 \mathrm{a}-\mathrm{e}$ & $87.43 a$ & Hindistan & $1.03 \mathrm{a}-\mathrm{e}$ & $87.43 a$ & Hindistan \\
\hline İslamabad & $1.10 \mathrm{a}-\mathrm{d}$ & $73.86 \mathrm{r}$ & İslamabad & $1.10 \mathrm{a}-\mathrm{d}$ & $73.86 \mathrm{r}$ & İslamabad \\
\hline K.T.Pop-1 & $1.00 \mathrm{a}-\mathrm{f}$ & $73.77 \mathrm{~s}$ & K.T.Pop-1 & $1.00 \mathrm{a}-\mathrm{f}$ & $73.77 \mathrm{~s}$ & K.T.Pop-1 \\
\hline K.T.Pop-2 & $1.33 a$ & $76.12 p$ & K.T.Pop-2 & $1.33 a$ & $76.12 p$ & K.T.Pop-2 \\
\hline Karaman & $1.13 \mathrm{abc}$ & $81.95 \mathrm{~h}$ & Karaman & 1.13abc & $81.95 \mathrm{~h}$ & Karaman \\
\hline Kerkük F-2 & $0.70 \mathrm{e}-\mathrm{h}$ & 78.371 & Kerkük F-2 & $0.70 \mathrm{e}-\mathrm{h}$ & 78.371 & Kerkük F-2 \\
\hline Kıșehir & $1.10 \mathrm{a}-\mathrm{d}$ & $84.77 \mathrm{c}$ & Kıșehir & $1.10 \mathrm{a}-\mathrm{d}$ & $84.77 \mathrm{c}$ & Kıșehir \\
\hline Kișniș Pop & $0.73 \mathrm{~d}-\mathrm{h}$ & 78.02no & Kişniș Pop & $0.73 \mathrm{~d}-\mathrm{h}$ & 78.02no & Kişniș Pop \\
\hline Mardin B.T & $0.80 \mathrm{c}-\mathrm{h}$ & $69.28 \mathrm{t}$ & Mardin B.T & $0.80 \mathrm{c}-\mathrm{h}$ & $69.28 \mathrm{t}$ & Mardin B.T \\
\hline Nazilli & $0.63 \mathrm{f}-1$ & $83.73 d$ & Nazilli & $0.63 f-1$ & $83.73 d$ & Nazilli \\
\hline Rize Fındıklı & $1.13 \mathrm{abc}$ & $80.11 \mathrm{k}$ & Rize Findıklı & 1.13abc & $80.11 \mathrm{k}$ & Rize Fındıklı \\
\hline Ortalama & 0.89 & 75.03 & ortalama & 0.89 & 75.03 & Ortalama \\
\hline $\mathrm{F}$ & $4.4^{* *}$ & $13192.0^{* *}$ & $\mathrm{~F}$ & $4.4^{* *}$ & $13192.0^{* *}$ & $\mathrm{~F}$ \\
\hline
\end{tabular}

$* * \mathrm{p}<0.010 ̈$ nem seviyesi

$\beta$-pinene bileşeni ile ilgili yapılan çalıșmalara bakıldığında; Beyzi ve Güneş, (2017) \% 0.16 - 0.19, Yurum, (2012) \%0.01- \%0.36 değerlerinden oldukça yüksek çıkmıştır. Bu farklılığın, farklı genotipler, ekolojik koșullar ve ekim zamanlarından kaynaklandığı düşünülmektedir.

\section{Sonuç}

Kişniş ihracatı yapan ülkeler arasında yerimizi koruyabilmek kaliteli ve standartlara uygun ürün yetiștirebilmek için uygun ekolojik şartlarda, doğru yetiştirme teknikleri ile uygun çeşit kullanımı etkilidir. Çalışma sonucunda kişniş çeşit ve popülasyonlarından elde edilen verilere göre, incelenen özellikler bakımından materyaller arasında önemli farklılıklar bulunmuştur. Bolu ekolojik şartlarında tek yıllık olarak yürütülen bu çalışmada, kişniş tohum verimi bakımından Erzurum popülasyonu, uçucu yağ oranı bakımında K.T. Pop-2, linalool bakımından Hindistan popülasyonu öne çıkmakla birlikte, denemenin birkaç yıl daha tekrarlanması uygun olacaktır.

\section{Kaynaklar}

Anonim (2013). T.C Resmi Gazete, Türk Gıda Kodeksi Baharat Tebliği (28614) (Tebliğ No: 2013/12), 10 Nisan 2013.

Anonim (2016). T.C Tarım ve Köy İşleri Bakanlığı Tohumluk Tescil ve Sertifikasyon Merkezi, Kişniş Tescil Özet Raporu, 2004 Ankara.

Anonim (2015). Bolu İl Gıda Tarım ve Hayvancılık Müdürlüğü.http://www.tarim.gov.tr. [erişim tarihi 29 Ocak 2017].

Arslan, N., \& Bayrak, A. (1987). Farklı Ekim Zamanlarının Kimyonun (Cuminum cyminum L.) Verimine ve Bazı Özelliklerine Etkisi. Doğa Türk Tarım ve Ormancılık Dergisi, 11( 2); 275-280.

Avcl, A.B., Amir, Nia, R., \& Bayram, E. (2005). Bornova Koşullarında Yetiștirilen İran Kökenli Kişniş (Coriandrum sativum L.)'in verim ve Kalite Özellikleri, Türkiye VI. Tarla Bitkileri Kongresi, 5-9 Eylül 2005, Antalya.

Arabacı, B., \& Bayram, E. (2005). Farklı Sıra Arası ve Tohumluk Miktarlarında Kişniş (Coriandrum 
sativum L.)'in Bazl Morfolojik ve Teknolojik Özelliklerinin belirlenmesi. Türkiye VI. Tarla Bitkileri Kongresi, 5-9 Eylül 2005, Antalya

Baydar, H., \& Erbaş, S. (2014). Yağ Bitkileri Bilimi ve Teknolojisi. SDÜ Yayınları, Yayın No: 97, Isparta Baydar, H. (2013). Tıbbi ve Aromatik Bitkiler Bilimi ve Teknolojisi, Süleyman Demirel Üniversitesi Ziraat Fakültesi. 51, Isparta.

Baytop, T. (1984). Türkiye'de Bitkiler ile Tedavi. İstanbul Üniversitesi Eczacılık Fakültesi Yayınları, 40, İstanbul.

Bayram, E. (1992). Türkiye Kültür Anasonları (Pimpinella anisum L.) Üzerinde Agronomik ve Teknolojik Araștırmalar, Doktora Tezi, Ege Üniversitesi Fen Bilimleri Enstitüsü, İzmir.

BETUM, Bilimsel Endüstriyel ve Teknolojik Uygulama ve Araştırma Merkezi https://betum.ibu.edu.tr/ kromatografi Bolu [26 Şubat 2017].

Beyzi, E., \& Güneș, A., (2017). Kișniș (Coriandrum sativum L.) Bitkisinin Uçucu Yağ Bileșenleri Üzerine Bor Uygulamasının Etkileri. Gaziosmanpaşa Üniversitesi Ziraat Fakültesi Dergis, 34(1), 146-52.

Bhat, S., Kaushal, P., Kaur, M., \& Sharmal, H.K. (2014). Coriander (Coriandrium sativum L.) Processing Nutritional and Functional Aspects. African Journal of Plant Science, 8, 25-53.

Cioanca, O., Hritcu, L., Mihasan, M., \& Hancianu, M. (2013). Cognitive enhancing and antioxidant activities of inhaled coriander volatile oil in amyloid $\beta$ (1-42) rat model of alzheimer's disease. Physiol Behavior, 120, 193-202.

Demir, H. (2015). Kahramanmaraş Koşullarında Farklı Ekim Zamanlarının Kişniş (Coriandrum Sativum L.)'te Verim Ve Kalite Üzerine Etkisi, Yüksek Lisans Tezi, Kahramanmaraş Sütçü İmam Üniversitesi Fen Bilimleri Enstitüsü, Kahramanmaraş.

Diederichsen, A. (1996). Coriander - (Coriandrum sativum L.) Promoting the conservation and use of under utilized and neglected crops, The International Plant Genetic Resources Institute, Rome.

Gümüşçü, A., İpek, A., \& Gümüşçü, G. (2007). Tescilli Kişniş (Coriandrum sativum L.) Çeșitlerinin Çumra (Konya) Koşullarında Performanslarının Belirlenmesi. Türkiye VII. Tarla Bitkileri Kongresi, 25-27 Haziran 2007, Erzurum, 2, 521-525.

Gök, N. (2011). Farklı Zamanlarda Ekilen Kişniş (Coriandrum sativum L.) Çeşitlerinin Verim ve Kalite Özelliklerinin Belirlenmesi, Yüksek Lisans Tezi, Yüzüncü Yıl Üniversitesi Fen Bilimleri Enstitüsü, Van.
Gücük, F. (2014). Tokat Kazova Ekolojik Koşullarında Kışlık Ve Yazlık Yetiştirilen Kişniş (Coriandrum sativum L.) Çeșit Ve Hatlarının Agronomik ve Kalite Özeliklerinin Belirlenmesi. Yüksek Lisans Tezi, Gaziosmanpaşa Üniversitesi Fen Bilimleri Enstitüsü, Tokat.

İșcan, G., Demirci, F., Kırımer, N., Kurkcuoğlu, M., Bașer, K.H.C., \& Kıvanc, M. (2004). Bazı Umbelliferae Türlerinden Elde Edilen Uçucu Yağların Antimikrobiyal Etkileri. 14. Bitkisel İlaç Hammaddeleri Toplantısı, Bildiriler, Anadolu Üniversitesi Eczacılık Fakültesi, Eskișehir.

Kan, Y., \& İpek, A. (2002). Seçilmiş Bazı Kişniş (Coriandrum sativum L.) Hatlarının Verim ve Bazı Özellikleri, 14. Bitkisel İlaç Hammaddeleri Toplantısı, Eskișehir.

Kaya, N,, Yılmaz, G., \& Telci, İ. (2000). Farklı Zamanlarda Ekilen Kişniş (Coriandrum sativum L.) Popülasyonlarının Argonomik ve Teknolojik Özellikleri, Turkish Journal of Agriculture and Forestry, 24, 355364.

Karadoğan, T., \& Oral, E. (1994) Farklı Sıra Aralıkları Uygulanan Kişniş Varyetelerinin Verim ve Verim Unsurları ve Kalitesi Üzerine Bir Araștırma, Atatürk Üniversitesi Ziraat Fakültesi Dergisi, 25, 311-318.

Kalkan, Z. (2015). Kișniş Bitkisinin (Coriandrum sativum L.) Verim, Verim Unsurları Ve Bazı Kalite Özellikleri Üzerine Farklı Sıra Arası Mesafelerin Etkisi, Yüksek Lisans Tezi, Atatürk Üniversitesi Fen Bilimleri Enstitüsü, Erzurum.

Kandemir, K. (2010). Farklı Azot Dozu Ve Sıra Aralığının Kişnişin Verim ve Verim Unsurları Üzerine Etkisi, Yüksek Lisans Tezi, Ordu Üniversitesi Fen Bilimleri Enstitüsü, Ordu.

Kırıcl, S. (1999). Değișik Yörelerden Toplanan Kișniş (Coriandrum sativum L.)'in Bölgeye Adaptasyonu Ve Uygun Tohumluk Miktarının Belirlenmesi: Morfolojik Özellikleri Üzerine Tohumluk Miktarının Etkisi. Çukurova Üniversitesi Ziraat Fakültesi Dergisi, 14, 33-40.

Kırıcl, S., Mert, A., \& Ayanoğlu, F. (1997). Hatay Ekolojisinde Azot ve Fosforun Kişniş (Coriandrum sativum L.)'da Verim Değerleri ile Uçucu Yağ Oranlarına Etkisi. Türkiye II. Tarla Bitkileri Kongresi, 22-25 Eylül 1997, Samsun.

Kızıl, S., \& İpek, A. (2004) Bazı Kişniş (Coriandrum sativum L.) Hatlarında Farklı Sıra Arası Mesafelerinin Verim, Verim Özellikleri ve Uçucu Yağ Oranı Üzerine Etkileri. Tarım Bilimleri Dergisi, 10, 237244.

Mert, A., \& Kırıcı, S. (1998). Kişniş (Coriandrum sativum L.) Popülasyonlarının Verim ve Verim Karakterlerinin 
Belirlenmesi, XII. Bitkisel İlaç Hammaddeleri Toplantısı, 20-22 Mayıs 1998, Ankara.

Özel, A., Güler, İ., \& Erden, K. (2009). Harran Ovası Koşullarında Farklı Ekim Zamanlarının Kișniş (Coriandrum sativum L.)' in Verim ve Bazı Bitkisel Özelliklerine Etkisi. Harran Üniversitesi Ziraat Fakültesi Dergisi, 13, 41-48.

Özel, A., Koşar, İ. \& Kaan, E. (2010). Farklı Ekim Zamanlarının Kişniş (Coriandrum sativum L.) Uçucu Yağ Bileşenlerine Etkisi, Journal Agricultural Faculty Harran University, 14, 55-62.

Sezek, M. (2014). Farklı Ekim zamanlarının Kişniş (Coriandrium sativum L.) Çeşitlerinin Verim, Verim Unsurları ve Uçucu Yağ Oranına Etkisi, Yüksek Lisans Tezi, Atatürk Üniversitesi Fen Bilimleri Enstitüsü, Erzurum.

Şarer, E. (2000). Seçilmiş Kişniş (Coriandrum sativum L.) Hatlarında Yazlık ve Kışlık Ekimin Ürün kalitesine Etkisi, Ankara Üniversitesi Bilimsel Araştırma Projesi, Proje No: 2000-05-03-015.

Şanll, A., Karadoğan, T., \& Daldal, H. (2012). Burdur'da tarımı yapılan bazi umbelliferae türlerinin uçucu yağ oranı ve bileşenlerinin belirlenmesi. SDU J Fac Agric /SDÜ Ziraat Fak Derg.7(1), 27-31.

Telci, İ., Bayram, E., \& Avcl, B. (2006). Changes in Yield, Essential Oil and Linalool Contents of Coriandrum sativum Varieties (var. vulgare Alef. and var. microcarpum DC.) Harvested at Different Development Stages, European Journal of Horticultural Science, 71, 267-271.
TSE, (2015). Türk Standartları Enstitüsü, Standart Arama. Mevcut: https: //intweb.tse.org.tr/standard/ standard / standardara.aspx [21 Ocak 2015].

Turhan, H., Afat, O., \& Turhan, P. (2005). Bitki Sıklı̆̆ının Kişnişte (Coriandrum sativum L.) Verim ve Verim Unsurları Üzerine Etkisi, Türkiye VII. Tarla Bitkileri Kongresi. Cilt I, s:471-475, Antalya.

Tunçtürk, M. (2006). Kişniş (Coriandrum sativum L.) Bitkisinde Farklı Tohumluk Miktarlarının Verim, Verim Özellikleri ve Uçucu Yağ Oranı Üzerine Etkisi, Selçuk Üniversitesi Ziraat Fakültesi Dergisi, 20, 58-62.

Uhri, A. (2011). Boğaz Derdi, Arkeolojik, Arkeobotanik, Tarihsel ve Etimolojij Veriler Işığında Tarım ve beslenmenin kültür tarihi, Ege yayınları, $446 \mathrm{~s}$.

Wagner, H.M., Bladt, S., \& Zgainski, E.M. (1984). Plant drug analysis. New York: Springer-Verlag, 320p.

Yalçın, Z. (2016). Bazı Kişniş Genotiplerinin (Coriandrum sativum L.) Erzurum Ekolojik Koşullarında Verim ve Başlıca Tarımsal Özellikleri, Yüksek Lisans Tezi, Atatürk Üniversitesi Fen Bilimleri Enstitüsü, Erzurum.

Yurum, Ç. (2012). Samsun Ekolojik Koşullarında Kışlık ve Yazlık Ekim Zamanlarının Kişniş Bitkisinin (Coriandrum sativum L.) Önemli Tarımsal Özellikleri ile Kalite Kriterlerine Etkisinin Belirlenmesi, Yüksek Lisans Tezi, On dokuz Mayıs Üniversitesi Fen Bilimleri Enstitüsü, Samsun. 